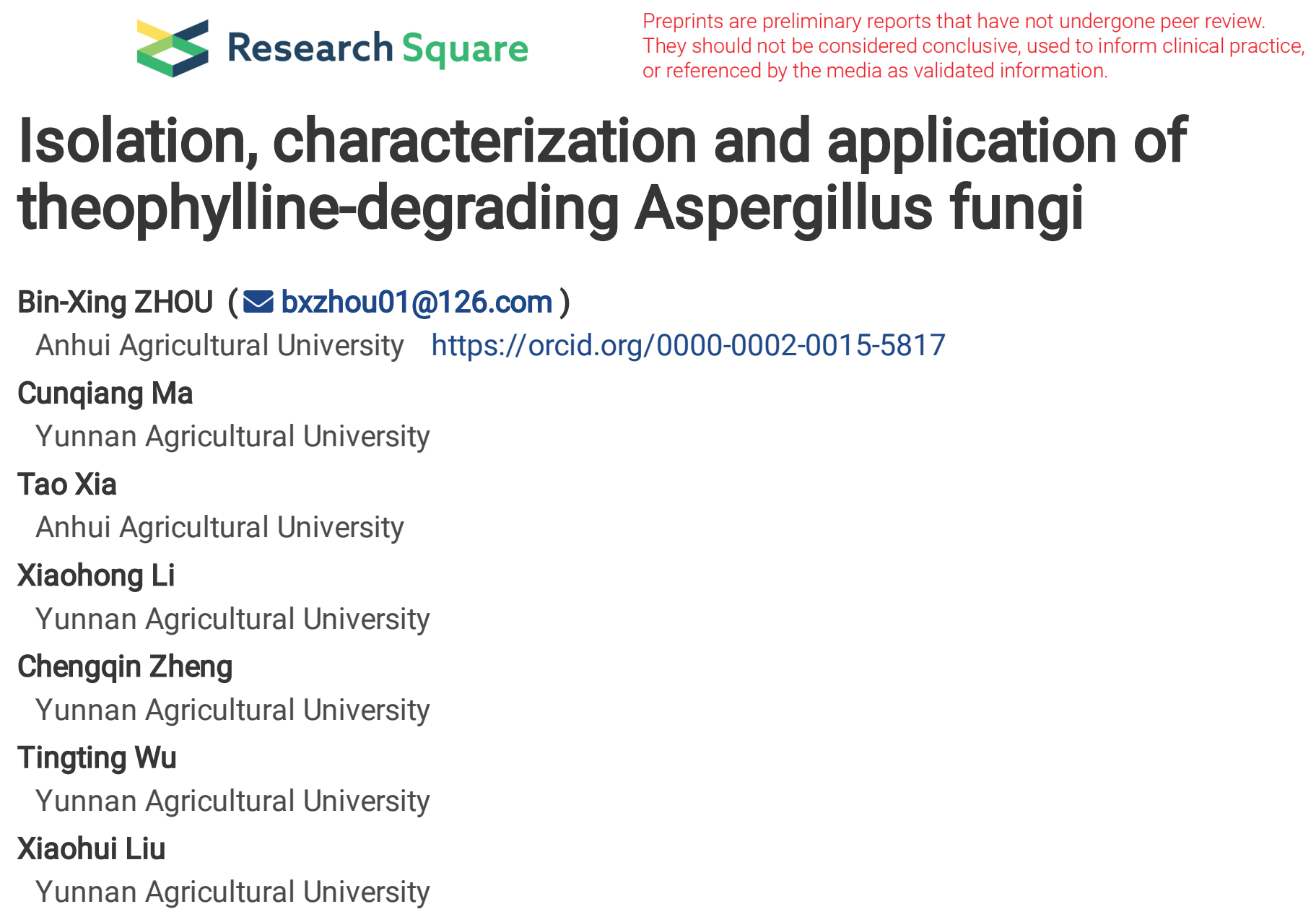

Bin-Xing ZHOU ( $\sim$ bxzhou01@126.com )

Anhui Agricultural University https://orcid.org/0000-0002-0015-5817

\section{Cunqiang $\mathrm{Ma}$}

Yunnan Agricultural University

\section{Tao Xia}

Anhui Agricultural University

\section{Xiaohong Li}

Yunnan Agricultural University

Chengqin Zheng

Yunnan Agricultural University

\section{Tingting Wu}

Yunnan Agricultural University

\section{Xiaohui Liu}

Yunnan Agricultural University

\title{
Research
}

Keywords: Aspergillus, Theophylline, 3-Methylxanthine, Bioconversion, Tea, Pathway

Posted Date: December 5th, 2019

DOI: https://doi.org/10.21203/rs.2.18212/v1

License: (a) (i) This work is licensed under a Creative Commons Attribution 4.0 International License. Read Full License 


\section{Abstract}

Background: Caffeine, theobromine and theophylline are main purine alkaloid in tea. Theophylline is the downstream metabolite and stays a very low level in Camellia sinensis. In our previous study, Aspergillus sydowii could convert caffeine into theophylline in solid-state fermentation of tea through $\mathrm{N}$ demethylation. In this study, tea-derived fungi caused theophylline degradation in the solid-state fermentation. The aim of this study was isolate theophylline-degrading fungi and to investigate their application in production of methylxanthines with theophylline as feedstock through microbial conversion.

Results: Of seven tea-derived fungi collected and identified by ITS, $\beta$-tubulin and calmodulin gene sequences, Aspergillus ustus, Aspergillus tamarii, Aspergillus niger and Aspergillus sydowii associated with solid-state fermentation of pu-erh tea have shown ability to degrade theophylline. A. ustus and A. tamarii could degrade theophylline highly significantly $(p<0.01)$ in liquid culture. 1,3-Dimethyluric acid, 3methylxanthine, 3-methyluric acid, xanthine and uric acid were detected consecutively by HPLC in A. ustus and $A$. tamarii respectively. The data from absolute quantification analysis suggest that 3methylxanthine and xanthine were main degraded metabolites in A. ustus and $A$. tamarii respectively. $129.48 \pm 5.81 \mathrm{mg} / \mathrm{L}$ of 3-methylxanthine and $159.11 \pm 10.8 \mathrm{mg} / \mathrm{L}$ of xanthine were produced by $A$. ustus and A. tamarii respectively in $300 \mathrm{mg} / \mathrm{L}$ of theophylline liquid medium.

Conclusions: For the first time, we confirmed that isolated Aspergillus ustus, Aspergillus tamarii degrade theophylline through $\mathrm{N}$-demethylation and oxidation. We were able to biologically produce 3-

methylxanthine and xanthine efficiently from theophylline through a new microbial synthesis platform with A. ustus and A. tamarii as appropriate starter strains.

\section{Background}

Caffeine (1, 3, 7-trimethylxanthine) is the most abundant methylxanthine alkaloids in tea, and also one of the major tea flavor constituents contributing to the bitter taste [1]. Caffeine was extensively established to be the final mathylxanthine product biosynthesized through three steps of the methylation of xanthisine in the root of tea tree [2]. Until now, the catabolism of caffeine has been relatively understood and established in plants, mainly in tea (Camellia sinensis) and caffeine (Coffea arabica) [3]. The major catabolic pathway of caffeine is as follows: caffeine $\rightarrow$ theobromine/theophylline $\rightarrow$ 3-methylxanthine $\rightarrow$ xanthine $\rightarrow$ uric acid $\rightarrow$ allantoin $\rightarrow$ allantoic acid $\rightarrow \mathrm{CO}_{2}+\mathrm{NH}_{3}[4,5]$. The other alternative catabolic pathways have been reported recently in Camellia plants [6,7]. The first demethylation happened at the position N-7 of caffeine and is the speed-limiting step for caffeine catabolism [8]. Theophylline (1,3-dimethylxanthine) is a transient metabolite and stays a very low level due to the slow metabolism in tea leaves [9].

Although caffeine level remains stable in the processing of general teas (green tea, black tea, oolong tea and white tea) $[10,11]$, several microorganisms have been selected from the soil of tea and coffee plantations to degrade caffeine, which included Pseudomonas putida [12, 13], Pseudomonas lutea [14], Serratia marcescens, Fusarium solani [15], Stemphyllium sp., Aspergillus tamarii, Penicillium commune 
[16]. Two possible mechanisms of caffeine catabolism in microorganisms are N-demethylation and oxidation [17]. Theophylline is the major metabolite formed in fungi through the $\mathrm{N}$-demethylation of caffeine, which present marked differences from bacteria that theobromine (3,7-dimethylxanthine) or paraxanthine (1,7-dimethylxanthine) are major metabolites in caffeine catabolism [17, 18]. Moreover, Pseudomonas putida was established to not only use caffeine, theobromine, paraxanthine (1,7dimethylxanthine), 7-methylxanthine as sole carbon and nitrogen sources, but also degrade theophylline and 3-methylxanthine [12, 19]. In addition, Aspergillus niger, Talaromyces marneffei, and Talaromyces verruculosus isolated from cocoa pod husks were established to degrade theobromine and produce methylxanthine (Mensah et al., 2018) [20]. However, only the bacterial strain Pseudomonas putida CBB5 was confirmed to degrade theophylline via N-demethylation (Yu et al., 2009; Algharrawi et al., 2015) [19, 21]. Until now, the theophylline-dagrading fungi and correlative metabolites were not completely definite.

Pu-erh tea is one of the most representative dark tea and natural microorganisms involved in solid-state fermentation (SSF) play an important role in tea processing [22, 23]. Microorganisms including bacteria and fungi have profound impact on substance metabolisms and correlation with quality formation of puerh tea $[24,25,26]$. Aspergillus niger, Aspergillus tubingensis, Aspergillus fumigatus, Aspergillus acidus, Aspergillus awamori, Aspergillus tamarii, Blastobotrys adeninivorans, Candida tropicalis, Fusarium graminearum, Pichia farinosa, Rasamsonia byssochlamydoides, Rasamsonia emersonii, Rasamsonia cylindrospora, Rhizomucor pusillus, Rhizomucor tauricus and Thermomyces lanuginosus have been detected in pu-erh tea $[27,28,29,30]$. Theophylline has several applications in therapeutics, especially as anti-asthmatic, anticancer, anti-cellutite and combinatorial drug [31, 32, 33]. Caffeine content is changing in pu-erh tea, which was associated with the fungi appearing in solid-state fermentation $[34,35,36,37,38]$. We found that theophylline content was increased significantly $(p<0.01)$ in the solid-state fermentation and Aspergillus sydowii cause caffeine degradation [39]. After in-depth research, Aspergillus sydowii has a significant $(p<0.05)$ impact on caffeine metabolism and has potential value in theophylline production through aerobic fermentation $[40,41]$.

In present study, we found that theophylline content had a highly significant $(p<0.01)$ decrease during the later period of solid-sate fermentation of pu-erh after a highly significant $(p<0.01)$ increase. Therefore, except for an isolated caffeine-degrading fungus identified as Aspergillus sydowii which caused the production of theophylline in the solid-state fermentation, theophylline-degrading fungi also could be found in the solid-state fermentation. In this paper, two theophylline-degrading fungi were isolated from the solid-state fermentation and identified as $A$. ustus and $A$. tamari based on colonial morphology and ITS, $\beta$ tubulin and calmodulin gene sequences, respectively. Theophylline degradation metabolites and pathways were analyzed in fungi by high-performance liquid chromatography (HPLC). The application in the production of methylxanthines was investigated by using $A$. ustus and $A$. tamarii.

\section{Methods}

\section{Materials and Reagents}


Sun-dried green tea leaves ( $C$. sinensis var. assamica) with moisture content $6.25 \%$ by weight were obtained from Yunnan province, China. Caffeine, theophylline, 3-methylxanthine, 1-methylxanthine, xanthine, 1,3-dimethyluric acid, 1-methyluric acid, 3-methyluric acid and uric acid were purchased from USA Sigma Company. SP fungal DNA kit was purchased from USA Omega Company. DNA marker, polymerase chain reaction (PCR) spread reagent, primers: ITS1 (5-TCGTAGGTG $\forall \mathbb{C} T G C G G-3$ ) and ITS4 (5-TCTCGC $\top A \top G A T A G C-3)$; Bt2a (5

$-G G T \forall \mathbb{C} \forall A T C G G T G C T G C \top T C-3)$ and $\mathrm{Bt} 2 \mathrm{~b}$ (5

- ACCTCAGTGTAGTGACC $\top G G C-3)$; and CF1L (5

- GCTGACTCG $\top G A \mathbb{C} G \forall G A G-3$ ) and CF4 (5

- $A \top \top T G C A T C A T G A G C T G \forall C-3$ ) were purchased from Japan TaKaRa company. Other reagents were ether analytical grade or chromatographic grade.

\section{Pu-erh tea solid-state fermentation, and determination of caffeine and theophylline}

The solid-state fermentation of pu-erh tea was based on the natural microbiota existing on the leaves and fermentation environment. A $2 \mathrm{~kg}$ sample of sun-dried green tea leaves was mixed with $885 \mathrm{~mL}$ tap water to achieve given moister content of $35 \%(\mathrm{w} / \mathrm{w})$ [29]. During the fermentation, the leaves were mixed to ensure homogeneity and tap water was added to keep the appropriate moisture content at $25-35 \%$. The whole fermentation continued for about 35 days and samples were collected every 5 days. The colony forming units (CFU) was calculated by per gram of the dry weight after 2 days of cultivation at $30^{\circ} \mathrm{C}$. Caffeine and theophylline contents was determined by high-performance liquid chromatography (HPLC) described by Zhou et al., [39, 40] using an Agilent 1200 series system and an Agilent $\mathrm{C}_{18}$ Chromatogram column $(250 \mathrm{~mm} \times 4.6 \mathrm{~mm}, 5 \mu \mathrm{m})$. The samples collected on day 20 and 25 were stored at $4{ }^{\circ} \mathrm{C}$ and selected for further isolation and identification of theophylline-degrading fungi.

\section{Fungal identification of isolates}

Fungal strains were isolated using potato dextrose agar (PDA) medium and they were counted by dilutionplating method (Wang, Peng and Gong, 2011). The colony forming units (CFU) was calculated by per gram of sun-dried tea leaves after 2 days of cultivation at $30^{\circ} \mathrm{C}$. Microscopic and morphological examinations of colonies were carried out according to mycological guide, and morphological features of their colonies are recorded in Table 1.

The fresh cells were obtained by centrifugation at $1700 \mathrm{~g}$ for $5 \mathrm{~min}$ after cultivation in $20 \mathrm{~mL}$ of Czapek Dox medium at $30^{\circ} \mathrm{C}$ for 2 days on an incubator shaker $(250 \mathrm{rpm})$ and freeze-dried at $-80^{\circ} \mathrm{C}$ [42]. DNA was extracted by using SP fungal DNA kit. The fungal primers ITS1 and ITS4, Bt2a and Bt2b, and CF1L and CF4 were used in the PCR to amplify the ITS, $\beta$-tubulin and Calmodulin regions, respectively [43]. The final volume of $50 \mu \mathrm{L}, 1.0 \mu \mathrm{L}$ of containing template DNA, $5 \mu \mathrm{L}$ of $10 \mathrm{x}$ buffer, $5 \mu \mathrm{L}$ of dNTPs $(2.5 \mathrm{mM}), 0.5 \mu \mathrm{L}$ of Taq polymerase, $1.0 \mu \mathrm{L}(10 \mu \mathrm{M})$ of each primer, and $36.5 \mu \mathrm{L}$ of sterile distilled water were used to 
implement amplifications $[23,42]$. The PCR reaction procedure was as follows. Pre-degeneration at $95^{\circ} \mathrm{C}$ for $5 \mathrm{~min}$, degeneration at $94{ }^{\circ} \mathrm{C}$ for $1 \mathrm{~min}$, annealing at $54^{\circ} \mathrm{C}$ for $1 \mathrm{~min}$, extension at $72{ }^{\circ} \mathrm{C}$ for $1.5 \mathrm{~min}$, with 35 cycles, extension at $72^{\circ} \mathrm{C}$ for $10 \mathrm{~min}$ [44]. It was stored at $10^{\circ} \mathrm{C}$ in the end of the reaction process.

\section{Evaluation of growth of isolates in agar mediums}

Qualitative screenings were carried out on Petri dishes containing a solid culture medium with dextrose (2 $\% \mathrm{w} / \mathrm{v}$ ) (control culture) and a selection medium with theophylline instead of dextrose in three different concentrations: 600,1200 and $1800 \mathrm{mg} / \mathrm{L}$ per plate, respectively [39]. Fungal mycelia were transferred to the surfaces of the agar plates with an inoculating loop $(10 \mathrm{ul})$. Isolates were incubated at $30{ }^{\circ} \mathrm{C}$ for 5 days. Compared with the control culture; theophylline utilization capacity of the isolate was estimated by the size of the colony grown on the plates (Table 3).

\section{Assessment of theophylline-degrading fungi in different theophylline liquid mediums}

Theophylline liquid medium (TLM) composed of $(\mathrm{g} / \mathrm{L}) \mathrm{NaNO}_{3}, 4.0 ; \mathrm{KH}_{2} \mathrm{PO}_{4}, 1.3 ; \mathrm{Na}_{2} \mathrm{HPO}_{4} \cdot 7 \mathrm{H}_{2} \mathrm{O}, 0.19$; MgSO4, 0.15; $\mathrm{CaCl}_{2} \cdot 2 \mathrm{H}_{2} \mathrm{O}, 0.26 ; \mathrm{MgSO}_{4} ; 0.15$; sucrose, 2.0 and theophylline, 0.3 in distilled water was prepared [45]. The isolate strains were transferred into PDA medium and incubated aerobically at $30{ }^{\circ} \mathrm{C}$ for $72 \mathrm{~h}$ on an incubator shaker ( $250 \mathrm{rpm})$, respectively. The spore suspension was adjusted to $1.0 \times 10^{7}$ $\mathrm{CFU} / \mathrm{mL}$ for inoculation after eluting by using sterile saline solution with identical theophylline concentration. To investigate the influence of carbon and nitrogen source on theophylline degradation, the modifications used either $5 \mathrm{~g} / \mathrm{L}$ sucrose or $10 \mathrm{~g} / \mathrm{L}$ dextrose as carbon source in theophylline liquid medium with sucrose as carbon source (TLM-S) or theophylline liquid medium with dextrose as carbon source (TLM-D), and $1.01 \mathrm{~g} / \mathrm{L}$ ammonium sulphate as nitrogen source in theophylline liquid medium with ammonium sulphate as nitrogen source (TLM-N), and $5 \mathrm{~g} / \mathrm{L}$ sucrose and $1.01 \mathrm{~g} / \mathrm{L}$ ammonium sulphate in theophylline liquid medium with sucrose and ammonium sulphate as carbon and nitrogen sources (TLM$\mathrm{SN}$ ), respectively. The spore suspension and liquid mediums were adjusted for $\mathrm{pH} 6.0$ by phosphate buffer. For each isolate, control and experimental mediums ( $25 \mathrm{~mL}$ each) were inoculated with spore suspension with $4 \%$ inoculum size $(\mathrm{v} / \mathrm{v})$ that $1 \mathrm{~mL}$ spore suspension was inoculated into each medium, and biocidal treatment was defined as the control. Theophylline concentration was determined after cultivation at $30^{\circ} \mathrm{C}$ for 5 days on an incubator shaker (130 rpm), respectively.

\section{Analysis of theophylline degradation metabolites by selected isolates}

Through comparison, sucrose as carbon source could promote theophylline degradation. Therefore, TLM-S was chose as the optimal medium to analyze theophylline degradation by selected isolates. A series of TLM-S mediums with different initial theophylline concentrations (100, 200 and $300 \mathrm{mg} / \mathrm{L}$, respectively) were set up each day of incubation and a 7-day period cultivation of each selected isolates were carried out on an incubator shaker $\left(130 \mathrm{rpm}, 30^{\circ} \mathrm{C}\right)$. At intervals of up to $24 \mathrm{~h}$ for 7 days, an aliquot of each 
culture was filtered through a 0.45 um syringe filter, and theophylline concentration and related metabolites were determined by high-performance liquid chromatography (HPLC) according to the method from Mensah et al. [20].

Standard calibration curves were prepared from solutions of theophylline, 3-methylxanthine, 1methylxanthine, xanthine, 1,3-dimethyluric acid, 1-methyluric acid, 3-methyluric acid and uric acid. $2 \mathrm{~mL}$ aliquots from each collected culture were filtered and analyzed by HPLC for heophylline, 3-methylxanthine, 1-methylxanthine, xanthine, 1,3-dimethyluric acid,1-methyluric acid,3-methyluric acid and uric acid. Internal standard method was used to aid in identification of metabolites. The concentrations of main degradation products (3-methylxanthine and xanthine) were analyzed in inoculated culture medium by selected isolates.

\section{Influence of selected isolates on 3-methylxanthine and xanthine}

Analysis of theophylline degradation products showed that $\mathrm{N}$-demethylation was the main theophylline degradation pathway in fungi, and 3-methylxanthine and xanthine were main demethylated products. To explore the effects of selected isolates on 3-methylxanthine and xanthine, 3-methylxanthine and xanthine liquid mediums were prepared as above described with $5 \mathrm{~g} / \mathrm{L}$ sucrose as carbon source and $0.3 \mathrm{~g} / \mathrm{L} 3$ methylxanthine or $0.3 \mathrm{~g} / \mathrm{L}$ xanthine, respectively. Each isolate was inoculated with $4 \%$ inoculum size (v/v) and biocidal treatment was defined as the control. 3-Methylxanthine and xanthine concentrations were determined by HPLC after cultivation at $30^{\circ} \mathrm{C}$ for 5 days on an incubator shaker (130 rpm), respectively.

\section{Statistical analysis}

Three biological replications were carried out to ensure validity and repeatability. All data are presented as mean value \pm standard deviation (SD). The independent t-test using SPSS 20.0 for window was carried out to determine whether the significant difference at $p<0.05$ level or the highly significant difference in $p<$ 0.01 level exist by using one-way analysis of variance (one-way ANOVA) .

\section{Results}

\section{Theophylline degradation exists in solid-state fermentation of pu-erh tea}

Fungi count, caffeine and theophylline contents were determined in the natural solid-state fermentation of pu-erh tea, and results are presented in Figure 1. Fungi count (Fig. 1A) dramatically increased from day 0 to 10 and then increased slowly before day 20 . After day 20, fungi count maintained a high level overt $1.0 \times$ $10^{5} \mathrm{CFU} / \mathrm{g}$. Because of the metabolic activity of fungi, caffeine content (Fig. 1B) was decreased highly significantly $(p<0.01)$ from $36.85 \pm 1.02 \mathrm{mg} / \mathrm{g}$ to $25.46 \pm 1.85 \mathrm{mg} / \mathrm{g}$ during fermentation. Theophylline content (Fig. 1C) was increased highly significantly $(p<0.01)$ before day 20 , which confirmed that 
caffeine-degrading fungi leaded to caffeine degradation and theophylline production. In our previous study [40], it was found that Aspergillus sydowii convert caffeine to theophylline. However, after day 20, theophylline content had a highly significant $(p<0.01)$ decrease from $11.18 \pm 1.10 \mathrm{mg} / \mathrm{g}$ to $5.89 \pm 0.65$ $\mathrm{mg} / \mathrm{g}$, which shown that theophylline degradation appeared in solid-state fermentation except for caffeine degradation. Therefore, in consideration of fungal community, there existed theophylline-degrading fungi in the solid-state fermentation, which could be Aspergillus sydowii or other fungi.

\section{Isolation and identification of theophylline-degrading fungi}

Based on colony morphology, eleven filamentous fungi were initially selected and isolated from pu-erh tea. Among them, seven fungi were superior in number and coded orderly with numbers PT-1 to PT-7. Distinctive morphological features of the seven isolates were observed after cultivation at $30^{\circ} \mathrm{C}$ for 5 days and documented in Table 1.

\section{Table 1 Colony characteristics of theophylline-degrading fungi}

\begin{tabular}{|llllll|}
\hline Isolate & Shape & Surface & Colour & Exudate & Reference \\
\hline PT-1 & Circular & Rough & Black & None & {$[39]$} \\
\hline PT-2 & Circular & Rough & Olive green & Red-coloured & {$[39]$} \\
\hline PT-3 & Circular & Rough & $\begin{array}{l}\text { Dark yellow colonies with white } \\
\text { edges }\end{array}$ & $\begin{array}{l}\text { Yellow } \\
\text { sclerotium }\end{array}$ & {$[40]$} \\
PT-4 & Irregular & Rough & Light yellow & $\begin{array}{l}\text { Yellow } \\
\text { sclerotium }\end{array}$ & {$[40]$} \\
PT-5 & Circular & Rough & $\begin{array}{l}\text { Greyish-green centre with yellow } \\
\text { patches }\end{array}$ & Red pigment & {$[40]$} \\
PT-6 & Circular & Rough & Iron gray bulge with milk white edges & None & Figure S1 \\
\hline PT-7 & Irregular & Rough & Hazel green with gray back & None & Figure S2 \\
\hline
\end{tabular}

The amplified sequences of ITS region were produced with sizes ranging between 502 and 546 base pairs. The amplified sequences of $\beta$-Tubulin region were produced with sizes ranging between 420 and 694 base pairs. The amplified sequences of Calmodulin region were produced with sizes ranging between 715 and 765 base pairs. Based on the DNA sequences (Table 2), seven dominating isolates were belonged to 6 Aspergillus spp. and 1 Penicillium sp., respectively. Through Neighbor-Joining analysis for both new fungi (Additional file: Figure S5), in the phylogram for Aspergillus species (Figure S5a and S5b), strain PE-6 was clustered with Aspergillus ustus and showed a $100 \%$ of identity to the tested Aspergillus ustus NRRL275; additionally, PE-7 strain was closely related to Aspergillus tamarii NRRL20818 with 99.9\% of identity. 
Table 2 Identification of theophylline-degrading fungi by sequence determination

\begin{tabular}{|c|c|c|c|c|c|c|}
\hline Isolate & Primers & $\begin{array}{l}\text { Fragments } \\
\text { (bp) }\end{array}$ & Species & $\begin{array}{l}\text { Strain } \\
\text { number }\end{array}$ & identity & Reference \\
\hline PT-1 & ITS1/ITS4 & 546 & Aspergillus niger & NCBT110A & $99.8 \%$ & [39] \\
\hline PT-2 & ITS1/ITS4 & 516 & Aspergillus sydowii & NRRL250 & $99.8 \%$ & [39] \\
\hline \multirow{3}{*}{ PT-3 } & TS1/ITS4 & 541 & \multirow[t]{3}{*}{ Aspergillus pallidofulvus } & \multirow[t]{3}{*}{ NRRL4789 } & \multirow[t]{3}{*}{$99.9 \%$} & \multirow[t]{3}{*}{ [40] } \\
\hline & $\mathrm{Bt} 2 \mathrm{a} / \mathrm{Bt} 2 \mathrm{~b}$ & 516 & & & & \\
\hline & CF1L/CF4 & 765 & & & & \\
\hline \multirow{3}{*}{ PT-4 } & TS1/ITS4 & 532 & \multirow[t]{3}{*}{ Aspergillus sesamicola } & \multirow[t]{3}{*}{ CBS137324 } & \multirow[t]{3}{*}{$99.8 \%$} & \multirow[t]{3}{*}{ [40] } \\
\hline & $\mathrm{Bt} 2 \mathrm{a} / \mathrm{Bt} 2 \mathrm{~b}$ & 515 & & & & \\
\hline & CF1L/CF4 & 757 & & & & \\
\hline \multirow[t]{2}{*}{ PT-5 } & TS1/ITS4 & 525 & \multirow[t]{2}{*}{ Penicillium manginii } & \multirow[t]{2}{*}{ CBS253.31 } & \multirow[t]{2}{*}{$99.6 \%$} & \multirow[t]{2}{*}{ [40] } \\
\hline & $\mathrm{Bt} 2 \mathrm{a} / \mathrm{Bt} 2 \mathrm{~b}$ & 420 & & & & \\
\hline \multirow[t]{2}{*}{ PT-6 } & TS1/ITS4 & 502 & \multirow[t]{2}{*}{ Aspergillus ustus } & \multirow[t]{2}{*}{ NRRL275 } & \multirow[t]{2}{*}{$100 \%$} & \multirow[t]{2}{*}{ Figure S3 } \\
\hline & $\mathrm{Bt} 2 \mathrm{a} / \mathrm{Bt} 2 \mathrm{~b}$ & 694 & & & & \\
\hline \multirow[t]{3}{*}{ PT-7 } & TS1/ITS4 & 532 & \multirow[t]{3}{*}{ Aspergillus tamarii } & \multirow[t]{3}{*}{ NRRL20818 } & \multirow[t]{3}{*}{$99.9 \%$} & \multirow[t]{3}{*}{ Figure S4 } \\
\hline & $\mathrm{Bt} 2 \mathrm{a} / \mathrm{Bt} 2 \mathrm{~b}$ & 476 & & & & \\
\hline & CF1L/CF4 & 715 & & & & \\
\hline
\end{tabular}

\section{Evaluation results of theophylline-degrading fungi in solid mediums}

The screening was carried out in agar solid mediums for the evaluation of the biocatalytic potential for the degradation of theophylline. All isolate tea-derived strains were inoculated into an agar solid medium with the presence of dextrose and they were also inoculated into a set of agar solid mediums with increasing theophylline concentrations. The colony diameters of potential theophylline-degrading fungi were measured and showed in Table 3.

Table 3 Growth of tea-derived fungi in agar solid medium ( $2 \% \mathrm{w} / \mathrm{v})$ with dextrose $(2 \% \mathrm{w} / \mathrm{v})$ (control culture) or presence of theophylline instead of dextrose $\left(30^{\circ} \mathrm{C}, 5 \mathrm{~d}, \mathrm{pH} 7.0\right)$. 


\begin{tabular}{|c|c|c|c|c|}
\hline \multirow[t]{2}{*}{ Isolate fungi } & \multicolumn{4}{|c|}{ Colony diameter $(\mathrm{cm})$} \\
\hline & $\begin{array}{l}\text { Control } \\
\text { culture }\end{array}$ & $\begin{array}{l}600 \mathrm{mg} / \mathrm{L} \\
\text { theophylline }\end{array}$ & $\begin{array}{l}1200 \mathrm{mg} / \mathrm{L} \\
\text { theophylline }\end{array}$ & $\begin{array}{l}1800 \mathrm{mg} / \mathrm{L} \\
\text { theophylline }\end{array}$ \\
\hline A. niger & $3.5 \pm 0.5$ & $0.5 \pm 0.2$ & No growth & $1.0 \pm 0.5$ \\
\hline A. sydowii & $2.5 \pm 1.0$ & $0.5 \pm 0.1$ & $1.0 \pm 0.3$ & $0.5 \pm 0.3$ \\
\hline $\begin{array}{l}\text { A. } \\
\text { pallidofulvus }\end{array}$ & $3.0 \pm 0.5$ & No growth & No growth & $0.5 \pm 0.1$ \\
\hline $\begin{array}{l}\text { A. } \\
\text { sesamicola }\end{array}$ & $3.0 \pm 0.5$ & No growth & No growth & $0.5 \pm 0.1$ \\
\hline P. mangini & $3.0 \pm 1.0$ & No growth & No growth & No growth \\
\hline A. ustus & $2.5 \pm 0.5$ & $1.0 \pm 0.3$ & $1.5 \pm 0.4$ & $1.5 \pm 0.4$ \\
\hline A. tamarii & $3.0 \pm 0.5$ & $2.0 \pm 0.5$ & $2.5 \pm 0.5$ & $3.5 \pm 1.0$ \\
\hline
\end{tabular}

Six tea-derived strains could survive in the agar solid mediums $(2 \% \mathrm{w} / \mathrm{v})$ with theophylline alone. Aspergillus spp. showed a better growth in higher evaluated concentrations. Particularly, A. niger, $A$. sydowii, $A$. ustus and $A$. tamarii had growth in low theophylline concentration, which showed that these strains had a high utilization ratio of theophylline. A higher growth in lower concentration indicated a higher utilization of fungi direct or indirect [46]. Therefore, A. niger, A. sydowii, A. ustus and A. tamarii were considered as the potential theophylline-degrading fungi.

\section{Selection of theophylline-degrading fungi and optimal medium in liquid culture}

For theophylline biodegradation in liquid culture, with biocidal treatment as the control, seven isolates were inoculated into the basic mediums with the presence of theophylline and sucrose or dextrose as carbon source, or ammonium sulphate as nitrogen source, respectively. Theophylline concentration was determined after cultivation at $30^{\circ} \mathrm{C}$ for 5 days by HPLC and results are showed in Fig. 2. Through comparisons of each isolate, $A$. ustus and $A$. tamarii could decrease theophylline concentration high significantly $(\mathrm{p}<0.01)$ by about $65.15 \%$ and $95.98 \%$ in TLM-S medium, respectively. In addition, under the effect of $A$. niger and $A$. sydowii, theophylline concentrations were decreased slightly by about $1.03 \%$ and $5.19 \%$ in TLM-S medium, respectively, which showed that the theophylline utilizations of $A$. niger and $A$. sydowii were restricted. $A$. pallidofulvus, $A$. sesamicola and $P$. mangini had no significant $(\mathrm{p}>0.05)$ impact on theophylline degradation. Hence, $A$. ustus, $A$. tamarii, $A$. niger and $A$. sydowii were selected as the potential theophylline-degrading fungi for theophylline degradation in liquid culture.

Theophylline could be used as the sole carbon and nitrogen source. The presence of other carbon or nitrogen sources had a significant impact on theophylline degradation and pathway. The optimum liquid 
medium was chose by comparing theophylline degradation capacity in different mediums. In contrast with other mediums (TLM-D, TLM-N and TLM-SN), theophylline degradation level had a highly significant ( $\mathrm{c}$ 0.01) improvement in TLM-S medium, which showed that carbon source particularly sucrose promoted theophyline degradation and nitrogen source restrained theophylline degradation to a certain extent. Therefore, TLM-S medium was chose to analyze the characterization of theophylline degradation in liquid culture.

\section{Characterization of theophylline degradation by theophylline- degrading fungi}

A. ustus, A. tamarii, A. niger and A. sydowii were inoculated into TLM-S mediums with increasing theophylline concentrations (100, 200 and $300 \mathrm{mg} / \mathrm{L}$, respectively), and the Tissue-culture bottles were incubated in an orbital shaker $\left(130 \mathrm{rpm}, 30^{\circ} \mathrm{C}\right)$. The inoculation bottles were took every $24 \mathrm{~h}$ for the determination of theophylline and related metabolites by HPLC, and results are presented in Fig. 3. Under the effect of $A$. ustus and $A$. tamarii, theophylline content was decreased highly significantly $(p<0.01)$ in all substrate concentrations. However, the concentration of theophylline inoculated by $A$. niger and $A$. sydowii was slightly decreased $(\mathrm{p}>0.05)$ in all substrate concentrations. Therefore, $A$. ustus and $A$. tamarii had advantage in theophylline degradation than A. niger and A. sydowii. Both A. ustus and A. tamarii could degrade theophylline completely in low concentration (100 mg/L theophylline). However, $A$.

ustus only degrade $79.00 \%$ theophylline in high concentration ( $300 \mathrm{mg} / \mathrm{L}$ theophylline), while $A$. tamarii could degrade theophylline almost completely in all concentrations, which showed that $A$. tamarii had a higher theophylline degradation capacity.

A series of experiments was conducted to find out theophylline degradation pathway through the identification of catabolic intermediates by HPLC using internal standard method (Table 4). Related degradation metabolites were not found in the liquid culture inoculated by $A$. niger and $A$. sydowii. 1,3Dimethyluric acid, 3-methylxanthine, 3-methyluric acid, xanthine and uric acid were detected consecutively in the liquid culture. 3-Methylxanthine was common and main metabolite through $\mathrm{N}$-demethylation at the position $\mathrm{N}-1$ of theophylline in $A$. ustus and $A$. tamarii. Xanthine was the further demethylated metabolite in theophylline degradation found in $A$. ustus and $A$. tamarii through $\mathrm{N}$-demethylation at the position $\mathrm{N}-3$ of 3-methylxanthine. In contrast to $A$. ustus isolate that additional metabolites including 1,3-dimethyluric acid and 3-methyluric acid were identified in the culture through the oxidation of theophylline and 3methylxanthine, respectively [19]. Only uric acid was identified in $A$. tamarii culture as the oxidation product of xanthine, which showed the differences in degradation metabolites and pathways between $A$. ustus and $A$. tamarii.

Table 4 Theophylline degradation metabolites detected in the liquid media inoculated by Aspergillus fungi 


\begin{tabular}{|lllll|}
\hline Metabolite & \multicolumn{2}{l}{ Fungal isolates } \\
\cline { 2 - 5 } & A. ustus & A. tamarii & A. niger & A. sydowii \\
1,3-dimethyluric acid & + & - & - & - \\
1-methylxanthine & - & - & - & - \\
3-methylxanthine & + & + & - & - \\
1-methyluric acid & - & - & - & - \\
3-methyluric acid & + & - & - & - \\
\hline xanthine & + & + & - & - \\
\hline uric acid & - & + & - & - \\
\hline
\end{tabular}

TLM-S media were analyzed by HPLC for 1,3-dimethyluric acid, 1-methylxanthine, 3-methylxanthine, 1methyluric acid, 3-methyluric acid, xanthine and uric acid.

\section{Production of 3-methylxanthine or xanthine through theophylline degradation}

Several xanthine derivatives including 3-methylxanthine have been synthesized chemically for use in medical industry [47]. Except for engineering a microbial platform for de novo biosynthesis of diverse methylxanthins [48], bioconversion from cheaper feedstocks such as caffeine, theophylline and theobromine was an effective pathway to produce high value methylxanthines via metabolically engineered microorganisms [21]. In this study, $A$. ustus and $A$. tamarii could degrade theophylline, and 3methylxanthine and xanthine were detected as degradation metabolites. The microbial utilization of 3methylxanthine and xanthine were investigated as substrate through liquid culture of isolates. The concentrations of 3-methylxanthine and xanthine were determined by HPLC after cultivation for 5 days. As shown in Fig. $4, A$. ustus and $A$. tamarii had a significant $(p<0.05)$ or a highly significant $(p<0.01)$ impact on 3-methylxanthine degradation with a removal ratio of about $27.05 \%$ and $84.29 \%$, respectively. Associated with the metabolites in theophylline degradation, 3-methyluric acid and xanthine were 3methylxanthine degradation metabolites through oxidation and $\mathrm{N}$-demethylation, respectively.

Although A. ustus and A. tamarii could utilize 3-methylxanthine and xanthine significantly, 3mthylxanthine and xanthine concentrations were accumulated largely in theophylline degradation. To investigate the application in the production of 3-methylxanthine and xanthine using theophyllinedegrading fungi with theophylline as feedstock, the quantitative determination of 3-methylxanthine and xanthine were carried out in all theophylline concentrations inoculated by $A$. ustus and $A$. tamarii, respectively. The concentrations of 3-methylxanthine in $A$. ustus and $A$. tamarii cultures are presented in Fig. 5. We monitored the accumulation of 3-methylxanthine over the course of inoculated culture by $A$. ustus and $A$. tamarii. 3-Methylxanthine was detected in the culture medium after $24 \mathrm{~h}$ for the first time, and increased significantly with cultivation. Over a 7-day period cultivation of $A$. ustus (Fig. 5a), $49.68 \pm 2.97$ 
$\mathrm{mg} / \mathrm{L}, 83.82 \pm 3.35 \mathrm{mg} / \mathrm{L}$ and $129.48 \pm 5.81 \mathrm{mg} / \mathrm{L}$ of 3-methylxanthine were accumulated and increased significantly with increasing initial theophylline concentrations, respectively. Due to high degradation capacity of 3-methylxanthine in A. tamarii culture, 3-methylxanthine concentration (Fig. 5b) stayed at a low level that only $56.72 \pm 5.81 \mathrm{mg} / \mathrm{L}$ of 3-methylxanthine was accumulated in $300 \mathrm{mg} / \mathrm{L}$ of theophylline after a 7-day period cultivation. Hence, strain $A$. ustus exhibited a continuing accumulation of 3-methylxanthine over the course of liquid culture, and increasing initial theophylline concentrations could improve the production of 3-methylxanthine.

It is clear from the data presented in Fig. 6 that a reaction containing theophylline in A. tamarii culture provided linear conversion of theophylline to xanthine. Over a 7-day period cultivation of $A$. tamarii, $35.88 \pm$ $6.65 \mathrm{mg} / \mathrm{L}, 103.95 \pm 4.82 \mathrm{mg} / \mathrm{L}$ and $159.11 \pm 10.8 \mathrm{mg} / \mathrm{L}$ of xanthine were accumulated and increased significantly with increasing initial theophylline concentrations through $\mathrm{N}$-demethylation at the position $\mathrm{N}-3$ of 3-methylxanthine, respectively. Therefore, xanthine was main metabolite in theophylline degradation over the course of $A$. tamarii liquid culture, which showed that $A$. tamarii could be used for the production of xanthine with theophylline as feedstock through the microbial conversion.

\section{Discussion}

Although caffeine and related methyxanthines are toxic to most bacteria and invertebrates [49], some bacteria and fungi have evolved the ability to metabolize caffeine $[12,15]$. The certain microorganisms cause the decrease in caffeine level occasionally [36, 37]. In our previous studies [39, 40], it is found that caffeine content was decreased significantly and $A$. sydowii leaded to caffeine degradation. As the main metabolite, theophylline content was increased significantly and became the most abundant methylxanthine alkaloids instead of caffeine in pu-erh tea [41]. In this study, we confirmed that $A$. sydowii convert most of degraded caffeine to theophylline; otherwise, a new phenomenon (Fig. 1) that theophylline degradation was found in solid-state fermentation of pu-erh tea. This suggested that potential theophylline-degrading fungi utilizing theophylline as carbon or nitrogen sources could be found in fungal community.

Molecular identification of fungi is mostly dependent on PCR amplified sequences of ITS, $\beta$-Tubulin and Calmodulin genes, particularly the genera Aspergillus and Penicillium [50,51]. The amplified sequencing of ITS, $\beta$-Tubulin and Calmodulin regions, and colony morphology indicated that their seven candidate isolates were belonged to the Aspergillus and Penicillium genera, and identified specifically as $A$. niger, $A$. sydowii, A. pallidofulvus, A. ustus, A. sesamicola, A. tamarii and $P$. mangini. This was in line with the observation in literature that Aspergillus spp. and Penicillium spp. are amongst the filamentous fungal genera commonly associated with pu-erh tea [52,53,54], particularly A. niger, $A$. sydowii and $A$. tamarii having been widely reported as the dominant fungi in the solid-state fermentation of pu-erh tea.

The assessment in agar mediums with theophylline as sole carbon and nitrogen sources showed that six Aspergillus isolates could survive in theophylline agar medium, which suggested that those 6 candidate isolates (Table 3) used theophylline as carbon or nitrogen sources directly or indirectly. The data from the liquid culture inoculated by seven isolates with biocidal treatment as the control indicated that $A$. ustus 
and $A$. tamarii could degrade theophylline significantly $(p<0.05)$ or highly significantly $(p<0.01)$; moreover, the theophylline utilizations of $A$. niger and $A$. sydowii were restricted. Though the effect of $\mathrm{C} / \mathrm{N}$ ratio on growth is strain-dependent [55], increasing $\mathrm{C} / \mathrm{N}$ ratio would generally favour fungal growth, which influenced microbial metabolism to a certain degree. Through comparisons of theophylline degradation capacities in different theophylline liquid mediums containing sucrose or dextrose as carbon source, or ammonium sulphate as nitrogen source, sucrose enhanced theopylline degradation highly significantly ( $p$ $<0.01$ ). Therefore, TLM-S medium was the optimization for theophylline degradation and chose to analyze theophylline degradation metabolites in liquid culture.

Except for caffeine, theophylline and theobromine are main purine alkaloid in tea, which both have close connection with caffeine metabolism that theophylline is catabolite of caffeine and theobromine is precusor of caffeine biosynthesis in Camellia sinensis. As mentioned above, the pathway of caffeine degradation metabolism is comparatively clear in microorganisms that both $\mathrm{N}$-demethylation and oxidation were found in caffeine degradation, and $\mathrm{N}$-demethylation was main pathway in fungi $[17,18,56]$. In addition, several bacteria and fungi have been shown to be able to utilize or degrade theobromine, which include Pseudomonas putida, Aspergillus niger, Talaromyces marneffei, and Talaromyces verruculosus $[12,18,20]$. Mensah et al. confirmed the existence of subsequent demethylation and oxidation in theobromine degradation through the detection of correlative metabolites by HPLC under the effects of theobromine-degrading fungi [20]. However, theophylline degradation pathways and metabolites were not completely clear in fungi. In this study, it is confirmed that $A$. ustus and $A$. tamarii isolated from pu-erh tea could degrade theophylline in liquid culture. Based on the downstream metabolites detected in the liquid media, theophylline degradation pathways were established and shown in Fig. 7., which showed that both $\mathrm{N}$-demethylation and oxidation were theophylline degradation pathways found in $A$. ustus and $A$. tamarii. Theophylline and related demethylated metabolites can be oxidized to 1,3-dimethyluric acid, 3-methyluric acid and uric acid, respectively. The differences in the degradation metabolites suggested that $A$. ustus and $A$. tamari were different in degradation pathways, except the common pathway that theophylline $\rightarrow 3-$ methylxanthine $\rightarrow$ xanthine. Therefore, $\mathrm{N}$-demethylation was main theophylline degradation pathway, which was similar to caffeine catabolism and theobromine catabolism in fungi.

3-Methylxanthine and xanthine were common downstream metabolites detected in A. ustus and A. tamarii cultures. 3-Methylxanthine and other xanthine derivatives have been shown various biomedical effects as adenosine antagonist and inhibitors of Primary Amine Oxidase [57, 58]. Besides chemical synthesis, researchers produced methylxanthines in Escherichia coli strains that converts fed theophylline to 3methylxanthine, or using the microbial host Saccharomyces cerevisiae through de novo biosynthesis [21, 48]. Due to theophylline degradation characteristic, $A$. ustus and $A$. tamarii would be applied in the production of 3-methylxanthine and xanthine with theophylline as feedstock through microbial conversion. The differences in accumulated concentrations of 3-methylxanthine and xanthine suggested that $A$. ustus benefits the production of 3-methylxanthine, while $A$. tamarii benefits the production of xanthine. After a 7day period cultivation in $300 \mathrm{mg} / \mathrm{L}$ of theophylline liquid medium, $A$. ustus could produce $129.48 \pm 5.81$ $\mathrm{mg} / \mathrm{L}$ of 3-methylxanthine, and $A$. tamarii could produce $159.11 \pm 10.8 \mathrm{mg} / \mathrm{L}$ of xanthine, respectively. 


\section{Conclusions}

Our present work describes theophylline degradation pathways in tea-derived fungi, and explores the application in production of methylxanthines. A. ustus and $A$. tamarii isolated from solid-state fermentation of pu-erh tea and identified based on ITS, $\beta$-tubulin and calmodulin gene sequences, were confirmed to degrade theophylline significantly $(p<0.01)$ in liquid culture through the sequential selections. Extensive experiments were carried out to detect related degradation metabolites by using HPLC, finding N-demethylation and oxidation in theophylline catabolism. Through the absolute quantitative detection, it is showed that 3-methylxanthine and xanthine were main degraded metabolites in $A$. ustus and $A$. tamarii respectively, which suggests that $A$. ustus benefits the production of 3methylxanthine, while $A$. tamarii benefits the production of xanthine with theophylline as feedstock. This reports theophylline degradation pathway in Aspergillus fungi and represents a new microbial synthesis platform for production of methylxanthines using theophylline through the inoculation of $A$. ustus and $A$. tamarii respectively.

\section{Abbreviations}

SSF, solid-state fermentation; CFU, colony forming units;

HPLC, high-performance liquid chromatography; PDA, potato dextrose agar;

PCR, polymerase chain reaction; ITS, internal transcribed spacer;

dNTPs: deoxy-ribonucleoside triphosphates; TLM, theophylline liquid medium;

TLM-S, theophylline liquid medium with sucrose as carbon source;

TLM-D, theophylline liquid medium with dextrose as carbon source;

TLM-N, theophylline liquid medium with ammonium sulphate as nitrogen source;

TLM-SN, theophylline liquid medium with sucrose and ammonium sulphate as carbon and nitrogen sources; SPSS: Statistical product and service solutions; SD, standard deviation; ANOVA: Analysis of variance.

\section{Declarations}

\section{Ethics approval and consent to participate}

Not applicable

\section{Consent for publication}

Not applicable 


\section{Availability of data and materials}

The data that support the findings of this study are available from the corresponding author upon reasonable request.

\section{Competing interests}

The authors declare that they have no competing interests.

\section{Authors' contributions}

ZBX, MCQ and XT designed the study. ZBX and MCQ carried out the laboratory work for the study. LXH and ZCQ contributed to HPLC work. MCQ and WTT contributed to the fungal identification of the isolates. LXH contributed to the writing of the manuscript.

\section{Funding}

This work was supported by Modern Agricultural Tea Industry System of Yunnan Province, China (2017KJTX007), Modern Agricultural Industry Technology System of China (CARS-23) and National Natural Science Foundation of China (31560221). The funding bodies had no role in the design of the study, in data collection, analysis or interpretation, or in writing the manuscript.

\section{Acknowledgements}

We thank Yunnan University for the assistance in fungal identification.

\section{Authors' Information}

1. Long Run Pu-erh Tea College, Yunnan Agricultural University, Kunming 650201, Yunnan, China.

2. Kunming Dapu Tea Industry co., LTD, Kunming 650224,Yunnan, China.

3. State Key Laboratory of Tea Plant Biology and Utilization, Anhui Agricultural University, Hefei 230036,Anhui, China.

\section{References}

1. Horzic D, Komes D, Belscak A, Ganic KK, Ivekovic D, Karlovic D. The composition of polyphenols and methylxanthines in teas and herbal infusions. Food chem. 2009;115:441-448.

2. Mohanpuria P, Kumar V, Yadav SK. Tea caffeine: Metabolism, functions, and reduction strategies. Food Science and Biotechnology. 2010;19:275-287. 
3. Mazzafera P. Catabolism of caffeine in plants and microorganisms. Frontiers in Bioscience. 2004;9:1348-1359.

4. Ashihara H, Monteiro AM, Moritz T, Gillies FM, Crozier A. Catabolism of caffeine and related purine alkaloids in leaves of Coffea arabica L. Planta. 1996;198:334-339.

5. Zhu BY, Chen LB, Lu MQ, Zhang J, Han JY, Deng WW, Zhang ZZ 2019. Caffeine content and related gene expression: novel insight into caffeine metabolism in camellia plants containing low, normal,and high caffeine concentrations. J. Agric. Food Chem. 2019;67:3400-3411.

6. Wang W, Tang X, Hua F, Ling TJ, Wan XC, Bao GH. Camellimidazole A-C, three methylene- bridged dimeric imidazole alkaloids from Keemun black tea. Organic Letters. 2018;20(9):2672-2675.

7. Wang W, Zhu BY, Wang P, Deng WW, Wu GH, Wu FH, Ho CT, Liang TJ, Zhang ZZ, Wan XC, Bao GH. Enantiomeric trimethylallantoin monomers, dimers, and trimethyltriuret: Evidence for an alternative catabolic pathway of caffeine in tea plant. Organic Letters. 2019: 21:5147-5151.

8. Werner AK, Witte CP. The biochemistry of nitrogen mobilization: purine ring catabolism. Trend Plant Sci. 2011;16(7), 381-387.

9. Ashihara $\mathrm{H}$, Crozier A. Biosynthesis and metabolism of caffeine and related purine alkaloids in plants. Adv. Bot Res. 1999;30:117-205.

10. Wang LY, Wei K, Jiang YW, Cheng H, Zhou J, He W, Zhang CC., Seasonal climate effects on flavanols and purine alkaloids of tea (Camellia sinensis L.). Eur. Food Res. Technol.2011;233:1049-1055.

11. Zhu YC, Luo YH, Wang PP, Zhao MY, Li L, Hu XS, Chen F. Simultaneous determination of free amino acids in pu-erh tea and their changes during fermentation. Food Chem. 2016;194:643-649.

12. Yu CL, Summers RM, Li Y, Mohanty SK, Subramanian M, Pope RM. Rapid identification and quantitative validation of a caffeine-degrading pathway in Psedomonas CES. J Proteome Res. 2014;14:95-106.

13. Hakil M, Denis S, Gonzalez GV, Augur C. Degradation and product analysis of caffeine and related dimethyl xanthine by filamentous fungi. Enzyme Microb Tech. 1998;22:355-359.

14. Brand D, Pandey A, Roussos S, Rsoccol C. Biological detoxification of coffee husk by filamentous fungi using a solid state fermentation system. Enzyme Microb Tech. 2000;27(1):127-133.

15. Nanjundaiah S, Mutturi S, Bhatt P. Modeling of caffeine degradation kinetics during cultivation of Fusarium solani using sucrose as co-substrate. Biochemical Engineering Journal. 2017;125:73-80.

16. Dash SS, Gummadi SN. Degradation kinetics of caffeine and related methylxanthines by induced cells of Pseudomonas. Curr Microbiol. 2007;55:56-60.

17. Dash SS, Gummadi SN. Catabolic pathways and biotechnological applications of microbial caffeine degradation. Biotechnol Lett. 2006;28:1993-2002.

18. Gummadi SN, Dash SS, Devarai S. Optimization of production of caffeine demethylase by Pseudomonas in a bioreactor. J Industrial Microbiol Biotechnol. 2009;36:713-720.

19. Yu CL, Louie TM, Summers R, Kale Y, Gopishetty S, Subramanian M. Two distinct pathways for metabolism of theophylline and caffeine are coexpressed in Pseudomonas putida J Bacteriol. 2009;191(14):4624-4632. 
20. Mensah DO, Ocloo A, Lowor ST, Bonney EY, Okine LK, Adamafio A. Isolation and characterisation of theobromine-degrading filamentous fungi.Microbiol Res. 2018;206:16-24.

21. Algharrawi KH, Summers RM, Gopishetty S, Subramanian M. Direct conversion of theophylline to 3methylxanthine by metabolically engineered coli. Microb Cell Fact. 2015;14:203-215.

22. Jiang HY, Shii T, Matsuo Y, Tanaka T, Jiang ZZ, Kouno I. A new catechin oxidation product and polymeric polyphenols of post-fermented tea. Food Chem. 2011;129:830-

23. Abe M, Takaoka N, Idemoto Y, Takagi C, Imai T, Nakasaki K. Characteristic fungi observed in the fermentation process for puer tea. Int J Food Microbiol. 2008;124:199-203.

24. Zhao M, Xiao W, Ma Y, Sun TT, Yuan WX, Na T, Zhang DL, Wang YX, Li YL, Zhou HJ, Cui XD. Structure and dynamics of the bacterial communities in fermentation of the traditional Chinese post-fermented pu-erh tea revealed by 16S RNA gene clone library. World J Microb Biot. 2013;29(10):1877-1884.

25. Zhao M, Su XQ, Nian B, Chen LJ, Zhang DL, Duan SM,Wang LY, Shi XY, Jiang B, Jiang WW, Lv CY, Wang DP, Shi Y, Xiao Y, Wu JL, Pan YH, Ma Y. Integrated meta-omics approaches to understand the microbiome of spontaneous fermentation of traditional Chinese pu-erh tea. mSystems. 2019;4:e00680. DOl:1128/mSystems.00680-19

26. Wang B. Study on the correlation between microorganism and quality formation of pu'er tea during fermentation. Earth and Environmental Science. 2019;332:032055.doi:10.1088/17551315/332/3/032055

27. Zhang W, Yang RJ, Fang WJ, Yan L, Lu J, Sheng J, Lv J. Characterization of thermophilic fungal community associated with pile fermentation of pu-erh tea. Int J Food Microbiol. 2016;227:29-33.

28. Wang QP, Peng CX, Gong JS. Effects of enzymatic action on the formation of theabrownin during solid state fermentation of Pu-erh tea. J Sci Food Agr. 2011;91:2412-2418.

29. Zhao M, Zhang D., Su XQ, Duan SM, Wan JQ, Yuan WX, Liu BY, Ma Y, Pan YH. An integrated metagenomics/metaproteomics investigation of the microbial communities and enzymes in solidstate fermentation of pu-erh tea. Sci Rep. 2015;5:10117. http://www.nature.com/articles/srep10117.

30. Liang YR, Zhang LY, Lu JL. A study on chemical estimation of pu-erh tea quality. J Sci Food Agr.2005;85:381-390.

31. Lentini A, Tabolacci C, Mattioli P, Provenzano B, Beninati S. Antitumor activity of theophylline in cobination with paclitaxel: a preclinical study on elanoma expermental lung metastasis. Cancer Biother Radiophar. 2010;25:497-503.

32. Ma YJ, Jiang DQ, Meng JX, L, MX, Zhao HH, Wang Y, Wang LQ. Theophylline: a review of population pharmacokinetic analyses. J Clin Pharm Ther. 2016;41:594-601.

33. Shan Z, Rong W, Yang D, Yao P, Xie J, Liu L. Intravenous and nebulized magnesium sulfate for treating acute asthma in adults and children: a systematic review and meta-analysis. Resp Med. 2013;107(3):321-3

34. Zhang L, Li N, Ma ZZ, Tu PF. Comparison of the chemical constituents of aged pu-erh tea, ripened puerh tea, and other teas using HPLC-DAD-ESI-MS ${ }^{n}$. J Agr Food Chem.2011;59:8754-8760. 
35. Lv HP, Zhang YJ, Lin Z, Liang YR. Processing and chemical constituents of Pu-erh tea: A review. Food Res Int.2013;53:608-618.

36. Wang D, Xiao R, Hu XT, Xu KL, Hou Y, Zhong Y, Meng J, Fan BL, Liu LG. Comparative safety evaluation of Chinese Pu-erh green tea extract and Pu-erh black tea extract in Wistar rats. J Agr Food Chem. 2010;58:1350-1358.

37. Wang D, Xu KL, Zhang Y, Luo X, Xiao R, Hou Y, Bao W, Yang W, Yan H, Yao P, Liu LG. Acute and subchronic oral toxicities of Pu-erh black tea extract in Sprague-Dawley rats. J Ethnopharmacol. 2011;134:156-164.

38. Qin JH, Li N, Tu PF, Ma ZZ, Zhang L. Change in tea polyphenol and purine alkaloid composition during solid-state fungal fermentation of post-fermented tea. J Agr Food Chem. 2012;60: 1213-1217.

39. Zhou BX, Ma CQ, Wang HZ, Xia T. Biodegradation of caffeine by whole cells of tea-derived fungi Aspergillues sydowii, Aspergillus niger and optimization for caffeine degradation. BMC Microbiol. 2018;18:53. https://doi.org/10.1186/s12866-018-1194-8

40. Zhou BX, Ma CQ, Ren XY, Xia T, Li XH, Wu Y. Production of theophylline via aerobic fermentation of puerh tea using tea-derived fungi. BMC Microbial. 2019;19:261.https://doi.org /10.1186/s12866-019$1640-2$

41. Zhou BX, Ma CQ, Ren XY, Xia T, Li XH. LC-MS/MS-based metabolomic analysis of caffeine-degrading fungus Aspergillus sydowii during tea fermentation. J Food Sci. 2019;in press.

42. Wang QP, Gong JS, Chisti Y, Sirisansaneeyakul S. Fungal isolates from a pu-erh type tea fermentation and their ability to convert tea polyphenols to theabrownins. J Food Sci. 2015;80(4): M809-817.

43. Prencipe S, Siciliano I, Contessa C, Botta R, Garibaldi A, Gullino ML, Spadaro D. Characterization of Aspergillus section Flavi isolated from fresh chastnuts and along the chestnut flour process. Food Microbiol. 2018;69:159-169.

44. Haas D, Pfeifer B, Reiterich C, Partenheimer R, Reck B, Buzina W. Identification and quantification of fungi and mycotoxins from pu-erh tea. Int J Food Microbiol. 2013;166(2): 316-322.

45. Gutierrez-Sanchez G, Atwood J, Kolli VSK, Roussos S, Augur C. Initial proteome analysis of caffeineinduced proteins in Aspergillus tamarii using two-dimensional fluorescence difference gel electrophoresis. Appl Biochem Biotechnol. 2012;166:2064-2077

46. Alvarenga N, Birolli WG, Seleghim Mirna HR, Porto A. Biodegradation of methyl parathion by whole cells of marine-derived fungi Aspgillus sydowii and Penicillium decaturense. 2014:117:47-52.

47. Daly JW. Caffeine analogs: biomedical impact. Cell Mol Life Sci. 2007;64:2153-2159.

48. Mckeague M, Wang YH, Cravens A, Win MN, Smolke CD. Engineering a microbial platform for de novo biosynthesis of diverse methylxanthins. Metabolic Engineering. 2016; 38:191-203.

49. Hollingsworth RG, Armstrong JW, Campbell E. Pest control: caffeine as a repellent for slugs and snails. Nature. 2002;417:915-916.

50. Samson RA, Visagie CM, Houbraken J, Hong SB, Hubka V, Klaassen CHW, Perrone G, Seifert KA, Susca, A,Tanney JB, Varga J, Kocsube S, Szigeti G, Yaguchi T, Frisvad JC. Phylogeny, identification and nomenclature of the genus Aspergillus. Studies in Mycology. 2014;78:141-173. 
51. Houbraken J, Frisvad JC, Samson RA Taxonomy of Penicillium section Citrina. Studies in Mycology. 2011;70:53-138.

52. Tian JQ, Zhu ZX, Wu B, Wang L, Liu XZ. Bacterial and fungal communities in pu'er tea samples of different ages. J Food Sci. 2013;78(8):M1249-1256.

53. Zhang YJ, Skaar I, Sulyok M, Liu XZ, Rao MY, Taylor JW. The microbiome and metabolites in fermented pu-erh tea as revealed by high-throughput sequencing and quantitative multiplex metabolite analysis. PLoS One. 2016;11(6): e0157847 .DOI:10.1371/journal.pone.0157847

54. Zhao ZJ, Tong HR, Zhou L, Wang EX, Liu QJ. Fungal colonization of pu-erh tea in Yunnan. J Food Safety. 2010;30(4):769-784.

55. Gao L, Sun MH, Liu XZ, Che YS. 2007. Effects of carbon concentration and carbon to nitrogen ratio on the growth and sporulation of several biocontrol fungi. Microbiol Res. 2007;111(1): 87-92.

56. Mazzafera P, Olsson O, Sandberg G. Degradation of caffeine and related methyxanthines by Serratia marcescens isolated from soil under coffee cultivation. Microb Ecol. 1996;31:199-207.

57. Anaya AL, Cruz-Ortega R, Waller GR. Metabolism and ecology of purine alkaloids. Frontiers inBioscience. 2006;11:2354-2370.

58. Shanahan P, O'Sullivan J, Tipton KF, Kinsella GK, Ryan BJ, Henehan GTM. Theobroine and related methylxanthines as inhibitors of Primary Amine Oxidase. J Food Biochem. 2019;43:e12697. https://doi.org/10.1111/jfbc.12697.

\section{Additional Files}

Additional File 1: Figure S1. Colony characteristics $(a, b)$ and conidial structure $(c, d)$ of strain PE-6.

(a): Front on PDA medium at $25^{\circ} \mathrm{C}$ for 7 days. (b): Back on PDA medium at $25^{\circ} \mathrm{C}$ for 7 days.

(c) Mature conidia heads, conidia stems and antipodal cells (200x). (d): Hyohae, conidia stems and conidiums (400x).

Additional File 1: Figure S2. Colony characteristics $(a, b)$ and conidial structure $(c, d)$ of strain PE-7.

(a): Front on PDA medium at $25^{\circ} \mathrm{C}$ for 7 days. (b): Back on PDA medium at $25^{\circ} \mathrm{C}$ for 7 days.

(c) Conidia heads(200x). (d): Conidia stems, sterigmas and conidiums (400x).

Additional File 1: Figure S3. The received sequences of strain PT-6 (502bp ITS sequence and $694 \mathrm{bp}$ Calmodulin sequence).

Additional File 1: Figure S4. The received sequences of strain PT-7 (532bp ITS sequence,476bp $\beta$-tubulin sequence and 715bp Calmodulin sequence).

Additional File 1: Figure S5. Neighbor-Joining consensus trees of a Aspergillus ustus PE-6 and $\mathbf{b}$ Aspergillus tamarii PE-7. 
The identification was based on the ITS and Calmodulin genes for $A$. ustus PE- 6 , and the ITS, $\beta$-tubulin and Calmodulin genes for $A$. tamarii PE-7. The numbers over branches represent bootstrap confidence values (\%) based on 1000 replicates. The scale bar denotes the nucleotide substitution per sequence.

\section{Figures}
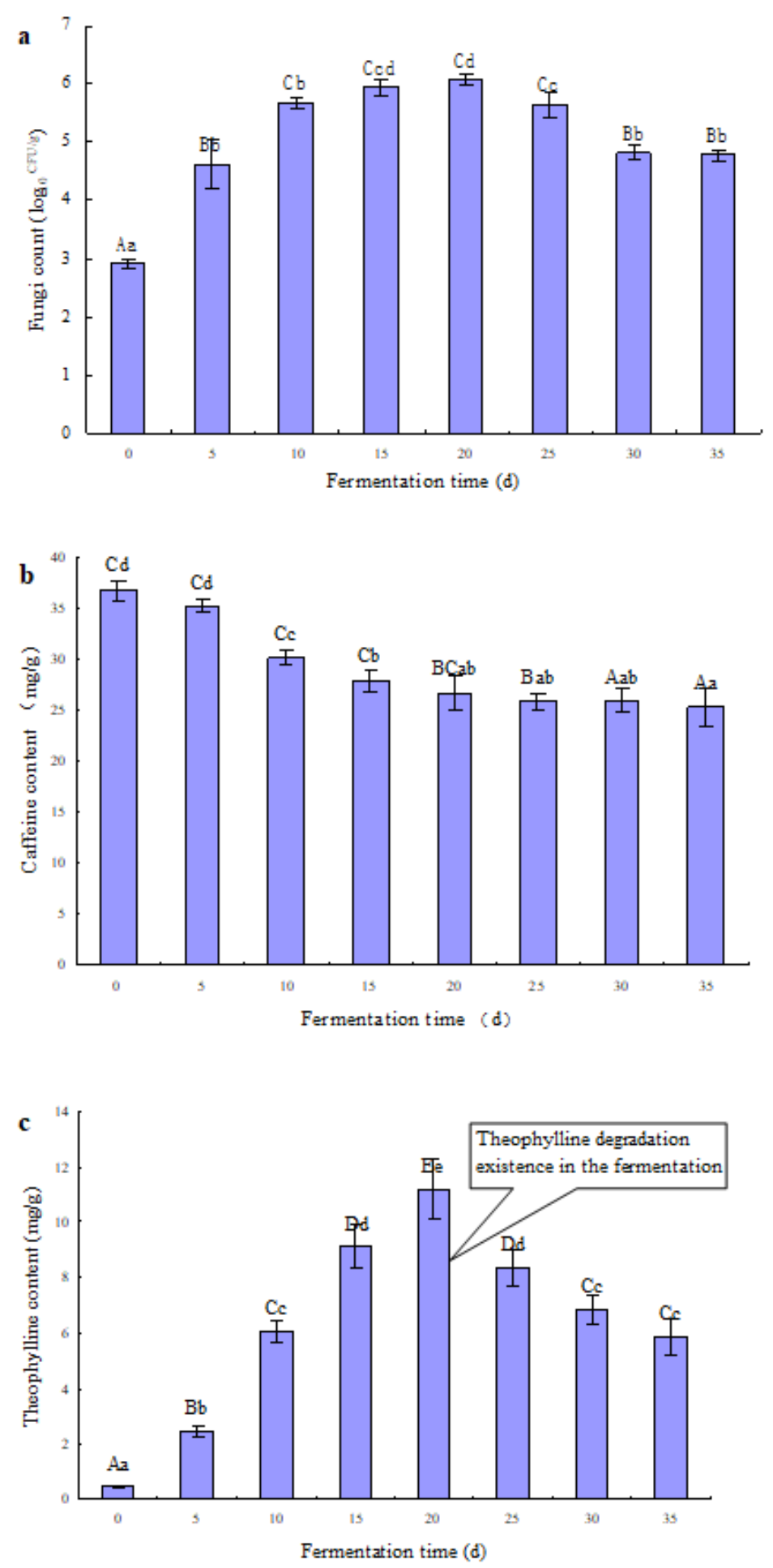

Figure 1 
Changes of fungi count (a), caffeine content (b) and theophylline content (c) during the soild-state fermentation of pu-erh tea. All data were present by mean value \pm SD of three replications. The lowercase letters indicated a significant difference at $p<0.05$ levels and the uppercase letters indicated a highly significant difference at $p<0.01$ levels using the independent t-test of SPSS 20.0. The different letters show significant differences.
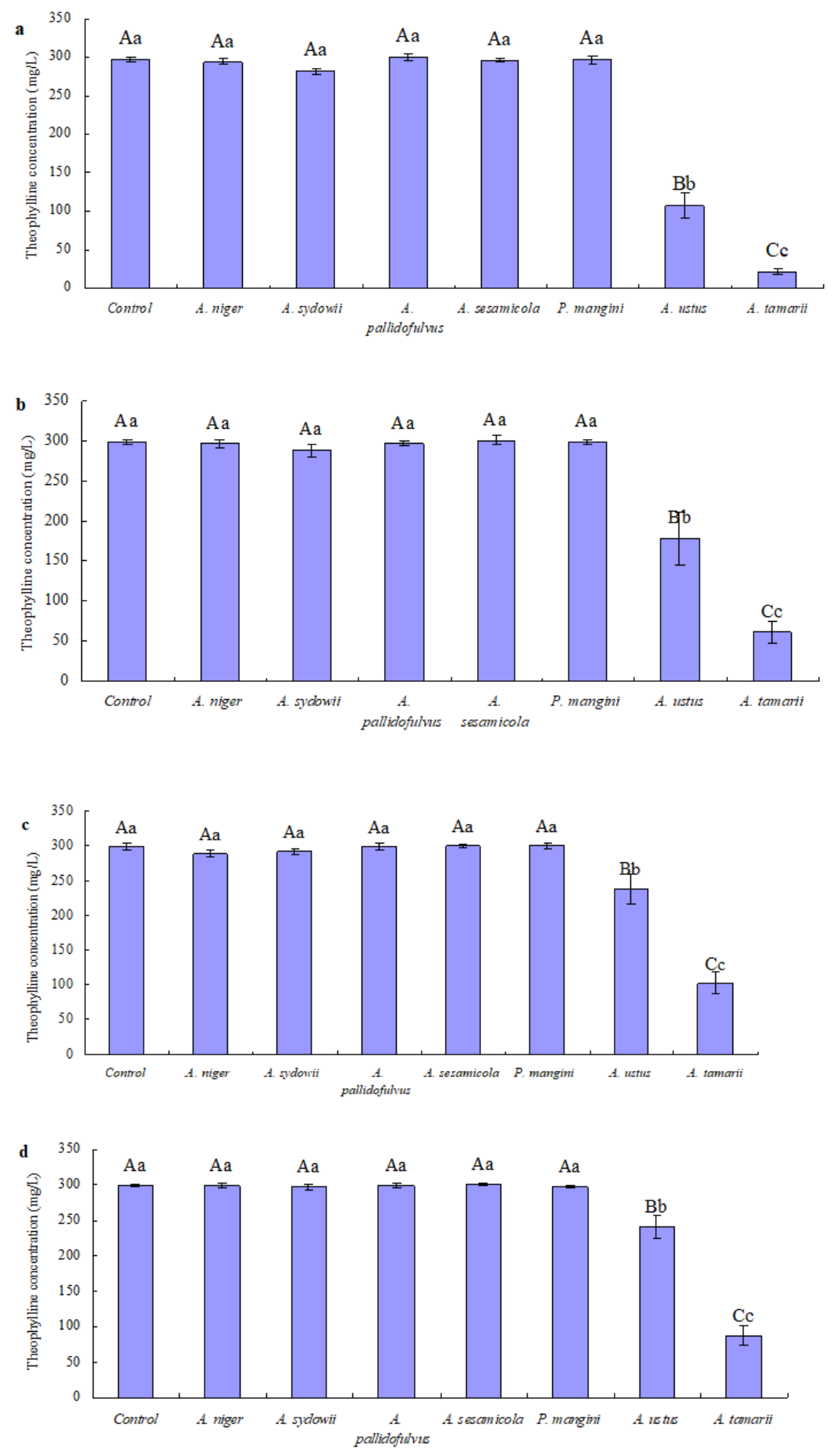

Figure 2 
Theophylline degradation capacity of isolate fungi strains in different theophylline liquid mediums. (a) TLM-S = theophylline liquid medium with sucrose as carbon source; (b) TLM-D = theophylline liquid medium with dextrose with sucrose as carbon source; (c) TLM-N = theophylline liquid medium with ammonium sulphate as nitrogen source; (d) TLM-SN = theophylline liquid medium with sucrose and ammonium sulphate as carbon and nitrogen sources, respectively. Biocidal treatment was defined as the control. All data were present by mean value \pm SD of three repKlications. The lowercase letters indicated a significant difference at $p<0.05$ levels and the uppercase letters indicated a highly significant difference at $p<0.01$ levels using the independent t-test of SPSS 20.0. The different letters show significant differences. 

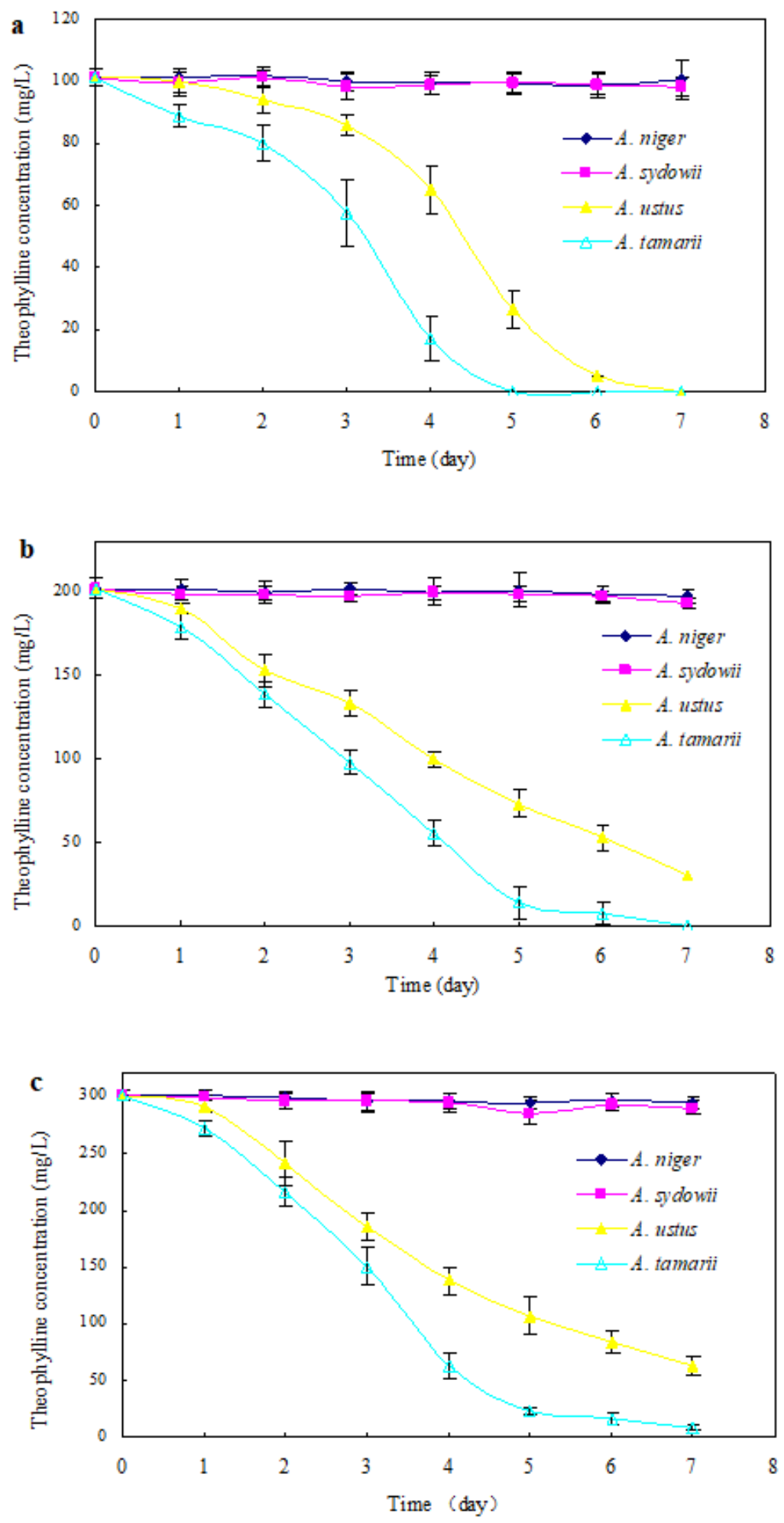

\section{Figure 3}

Effect of potential theophylline-degrading fungi on theophylline catabolism in different substrate concentrations. Theophylline concentrations were $100 \mathrm{mg} / \mathrm{L}$ (a), $200 \mathrm{mg} / \mathrm{L}$ (b), and $300 \mathrm{mg} / \mathrm{L}$ (c), respectively. All data were present by mean value \pm SD of three replications. 


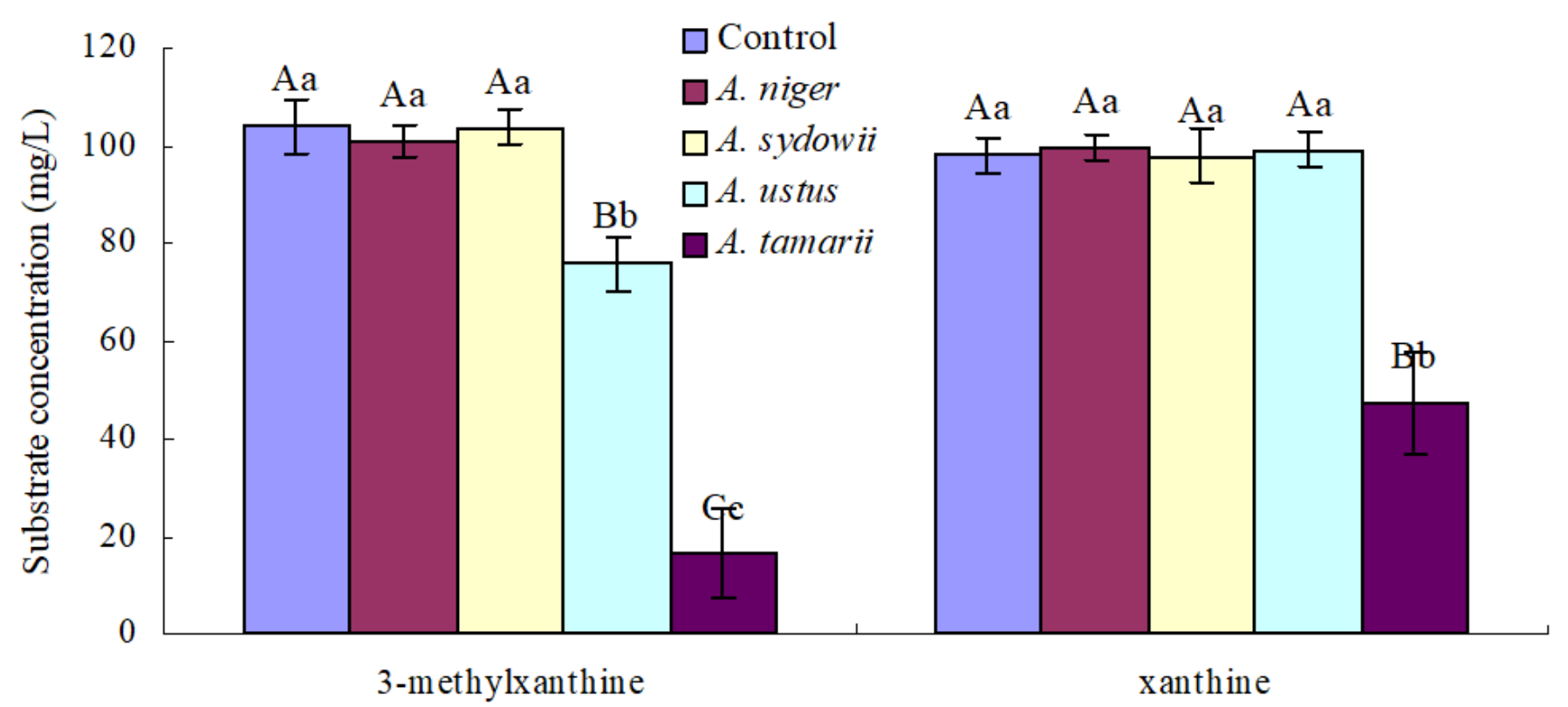

Figure 4

Effect of potential theophylline-degrading fungi on 3-methylxanthine and xanthine, respectively. Biocidal treatment was defined as the control. All data were present by mean value \pm SD of three replications. The lowercase letters indicated a significant difference at $p<0.05$ levels and the uppercase letters indicated a highly significant difference at $p<0.01$ levels using the independent t-test of SPSS 20.0. The different letters show significant differences. 

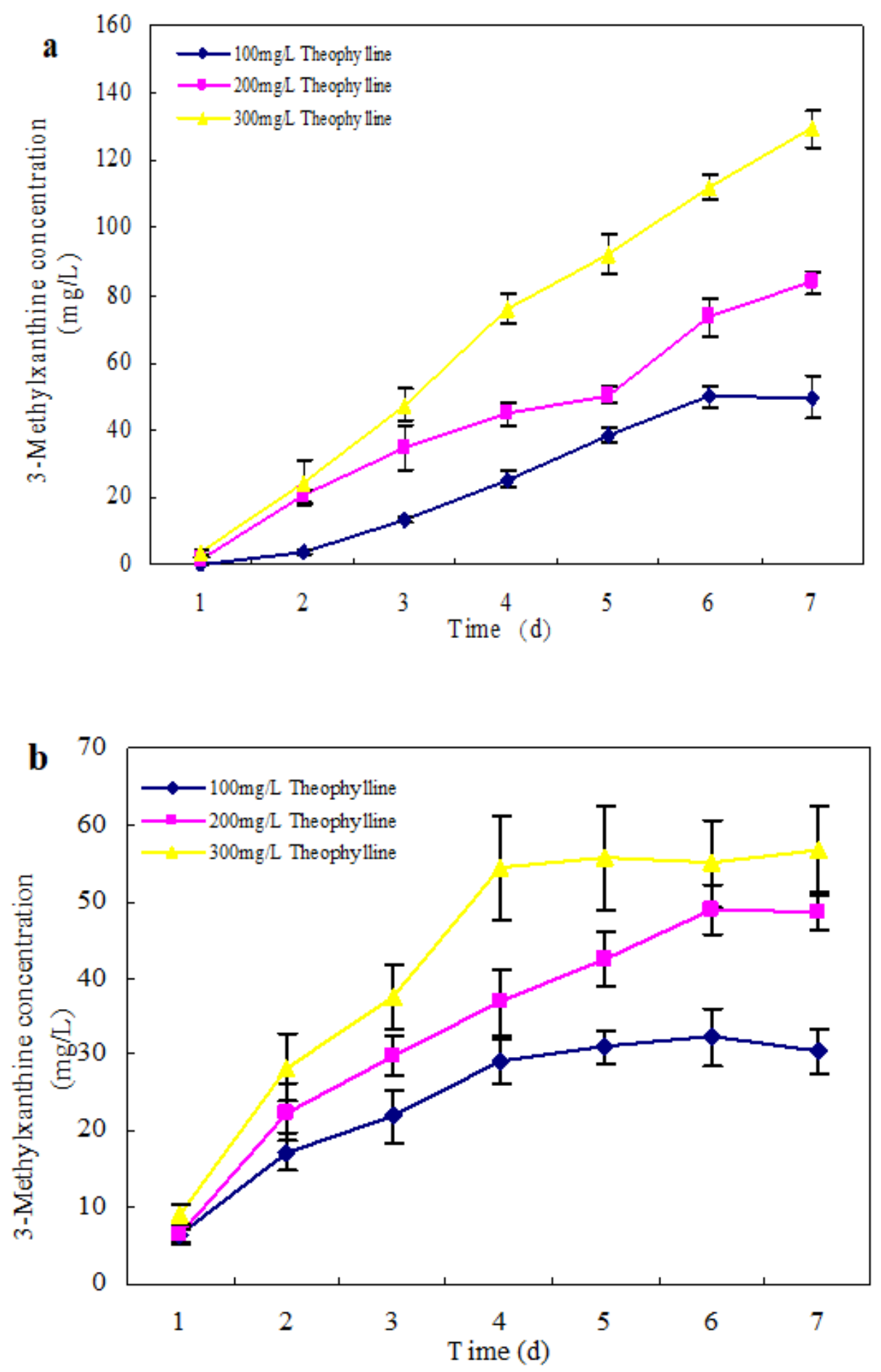

Figure 5

Effects of theophylline concentrations on 3-methylxanthine production by theophylline-degrading fungi. Liquid culture assays were performed using TLM-S mediums with different theophylline concentrations inoculated by Aspergillus ustus (a) and Aspergillus tamarii (b), respectively. Theophylline concentrations were $100 \mathrm{mg} / \mathrm{L}$ (filled rhombus), $200 \mathrm{mg} / \mathrm{L}$ (filled square), and $300 \mathrm{mg} / \mathrm{L}$ (filled triangle). Concentrations of 3-methylxanthine were present by mean value \pm standard deviations (SD) of three replications. 


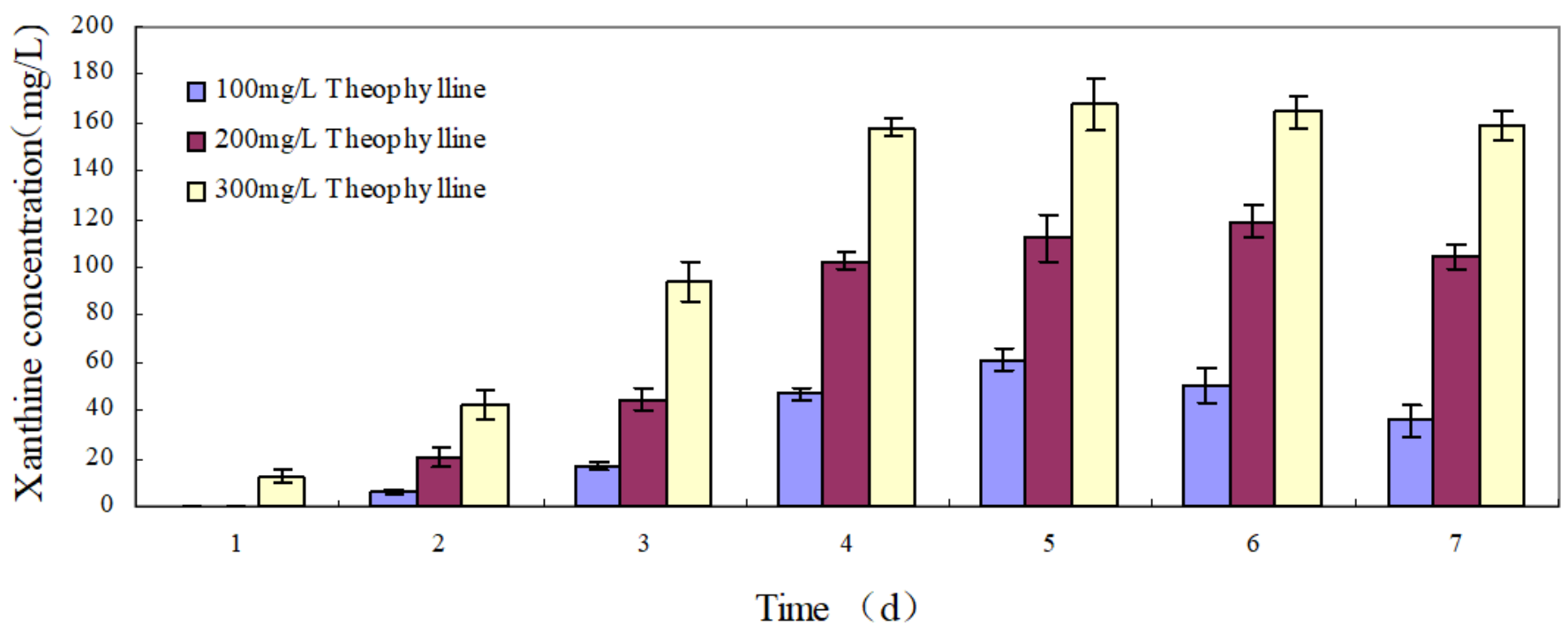

Figure 6

Effects of theophylline concentrations on xanthine production by Aspergillus tamarii. Liquid culture assays were performed using TLM-S mediums with different theophylline concentrations inoculated by Aspergillus tamarii, respectively. Concentrations of xanthine were present by mean value \pm standard deviations (SD) of three replications.
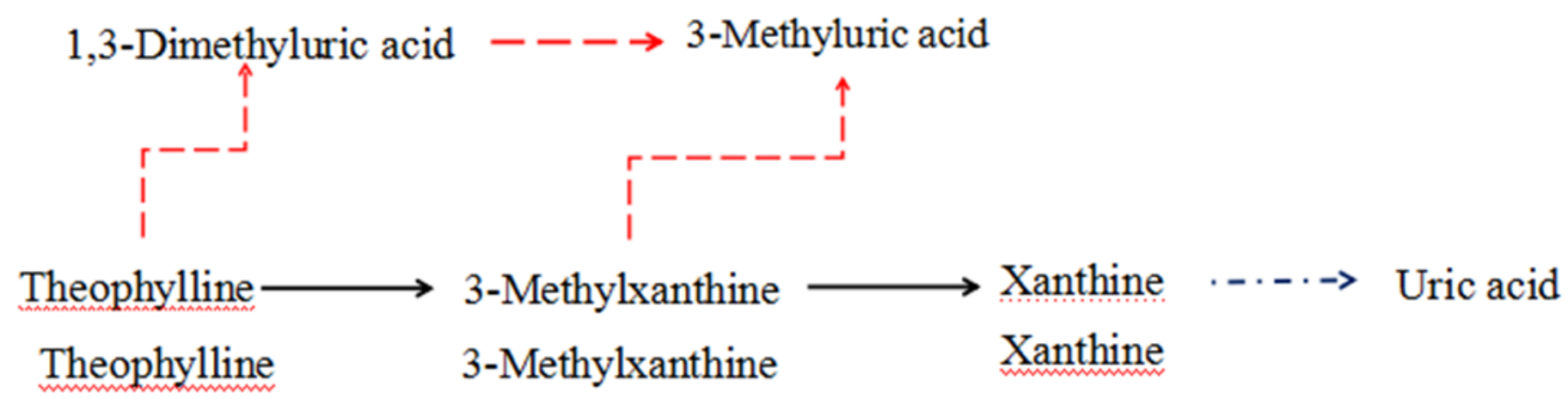<smiles>Cn1c(=O)c2[nH]cnc2n(C)c1=O</smiles><smiles>Cn1c(=O)[nH]c(=O)c2[nH]cnc21</smiles><smiles>O=c1[nH]c(=O)c2[nH]cnc2[nH]1</smiles>

\section{Figure 7}

Theophylline degradation pathways employed by A. ustus and A. tamarii. The black arrows ()indicate the common pathways to $A$. ustus and A. tamarii. The red arrows ( ) indicate a pathway detected for $A$. ustus only. The blue arrows ( ) indicate a pathway detected for A. tamarii only. 